\title{
Pathological Fracture of the Tibia as a First Sign of Hyperparathyroidism - A Case Report and Systematic Review of the Current Literature
}

\author{
ALEXANDER KEILER ${ }^{1}$, DIETMAR DAMMERER ${ }^{1}$, MICHAEL LIEBENSTEINER $^{1}$, \\ KATJA SCHMITZ ${ }^{2}$, PETER KAISER ${ }^{1}$ and ALEXANDER WURM ${ }^{1}$ \\ ${ }^{1}$ Department of Orthopaedics and Traumatology, Medical University of Innsbruck, Innsbruck, Austria; \\ ${ }^{2}$ Institute for Pathology, INNPATH GmbH, Innsbruck, Austria
}

\begin{abstract}
Background/Aim: Pathological fractures are rare, suspicious and in some cases mentioned as the first sign of a malignant tumor. We present an uncommon case with a pathological fracture of the tibia diaphysis as the first sign of severe hyperparathyroidism. Case Report: We report the case of a female patient who was referred to the emergency department with a history of progressively worsening pain in the lower left leg and an inability to fully bear weight. No history of trauma or any other injury was reported. An x-ray revealed an extensive osteolytic lesion in the tibial shaft with cortical bone destruction. Conclusion: Our case, together with very few cases described in the current literature, emphasizes that in the presence of hypercalcemia and lytic lesions primary hyperparathyroidism should always be considered as a differential diagnosis. Lytic bone lesions can lead to pathological fractures and severe impairment of quality of life.
\end{abstract}

Bone disease in severe primary hyperparathyroidism (PHPT) is described as osteitis fibrosa cystica (OFC). It was first described by von Recklinghausen in 1891 (1). However, at first von Recklinghausen did not suspect a relationship between OFC and a disease of the parathyroid glands (2).

Despite the fact that OFC is a highly rare and uncommon condition, clinically it is characterized by bone pain and radiographically by subperiosteal bone resorption, osteolysis

This article is freely accessible online.

Correspondence to: Alexander Keiler, MD, Ph.D., Department of Orthopaedics and Traumatology, Medical University of Innsbruck, Anichstrasse 35, 6020 Innsbruck, Austria. Tel: +43 51250422828, Fax: +43 51250422824, e-mail: alexander.keiler@i-med.ac.at

Key Words: Hyperparathyroidism, osteitis fibrosa cystica, brown tumor, pathological fracture, parathyroid gland. of the distal clavicles, a "salt and pepper" appearance of the skull, bone cysts, and brown tumors of the bones (3).

Primary hyperparathyroidism (PHPT), also known as "brown tumor", also involves unifocal or multifocal bone lesions, which represent a terminal stage of hyperparathyroidism-dependent bone pathology (4). This focal lesion is not a real neoplasm. In localized regions where bone loss is particularly rapid, hemorrhage, reparative granulation tissue, and active, vascular, proliferating fibrous tissue may replace the healthy marrow contents, resulting in a brown tumor.

Histologically, the tumor shows bland spindle cell proliferation with multinucleated osteoclastic giant cells and signs of bone resorption. The brown coloration is due to hemosiderin-laden macrophages. Multiple bony lesions representing brown tumors are often misdiagnosed as metastatic carcinoma, bone cysts, osteosarcoma, or giant-cell tumors. Histomorphologically, they might show high resemblance. Clinical information concerning hypercalcemia, hyperphosphatemia and hyperparathyroidism is indispensable for pathologic diagnosis and differentiation from giant cell tumor of the bone (5). Since the radiological features (e.g., cyst-like radiolucency) overlap and can be characteristic of these other diseases, diagnosis can be difficult (6-8). Parathyroidectomy is the treatment of choice in severe PHPT (9).

We report a case of primary hyperparathyroidism in which the first clinical manifestation of the disease was a pathological fracture of the tibia that masqueraded as a malignancy. The presence of large osteolytic lesions gave rise to the initial diagnosis of primary or metastatic cancer. Declaration of patient consent. All appropriate patient consent forms were obtained. In the form, the patient gave her consent for her images and other clinical information to be reported in the journal. The patient understands that neither her name nor her initials will be published and due efforts will be made to conceal her identity, but that anonymity cannot be guaranteed. 


\section{Case Report}

An 88-year-old Austrian Caucasian woman was referred to the emergency department with a history of progressively worsening pain in the left lower leg and inability to fully bear weight on the affected side. The patient reported no history of trauma, fall, or any other injury. An x-ray revealed an extensive osteolytic lesion in the tibial shaft with cortical bone destruction along with moth-eaten features (Figure 1). The patient had no history of weight loss, fever, or night sweats and had a negative family history for any tumors or disorders of calcium homeostasis. However, severe malnourishment and a cachectic nutritional condition were apparent. Despite her advanced age, the patient had no medical record of relevant pre-existing illnesses, and apart from inpatient stays for hip arthroplasty, the patient had never been in inpatient medical treatment. She lived alone at home, looked after by 24-h care, and was independently mobile with a rollator. Computed tomography (CT) scan showed a pathological fracture of the tibia in the distal third, with no dislocation. At the level of the pathological fracture, an approx. $4.7 \times 2.7 \mathrm{~cm}$ malignant bone lesion with approx. $23 \times 14 \mathrm{~mm}$ osteolysis on the ventral tibial corticalis, osseous thinning/beginning osteolytic dissolution of the dorsal tibial corticalis, and extraosseous soft tissue components with marginal calcification of the extraosseous soft tissue component were observed. Further distal (approx. $5.7 \mathrm{~cm}$ above the ankle joint), a second osteolysis of the medial tibial corticalis measuring approx. $17 \times 7 \mathrm{~mm}$ was seen, with accompanying soft tissue components, indicating a differential diagnosis of bone metastases or plasmacytoma (Figure 2). Initially, the fracture was stabilised with a leg cylinder cast and the patient was referred to a tertiary orthopaedic oncological center for further treatment and diagnostic findings.

Due to the pathological fracture, a haemato-oncological consultation was performed, as well as a sonographically targeted biopsy with further laboratory investigation. A wholebody CT scan as well as a CT scan of the skull and neck were performed, which revealed inhomogeneous texture of the cranial bone with numerous osteolytic destructions of the Tabula interna on both sides with small osteolytic defects also in the rest of the calvaria and minor osseous inhomogeneities in the mandible. No primary thoracic or abdominal malignancy was evident. Thus, radiologically the differential diagnosis of multiple myeloma was established.

However, the bone biopsy was consistent with a brown tumor, differential diagnostic giant cell tumor, or aneurysmatic bone cyst. The laboratory tests showed clearly deflected laboratory parameters with highly elevated parathyroid hormone (PTH) levels, lowered vitamin D3 levels, lowered folic acid levels, and lowered vitamin B12. In detail, PTH was highly elevated at 1,224 pg/ml (norm 15-65 pg/ml), while serum calcium was only slightly elevated at $2.60 \mathrm{mmol} / \mathrm{l}$ (norm 2.20-2.55 mmol/l). Serum phosphorus was $0.5 \mathrm{mmol} / 1$

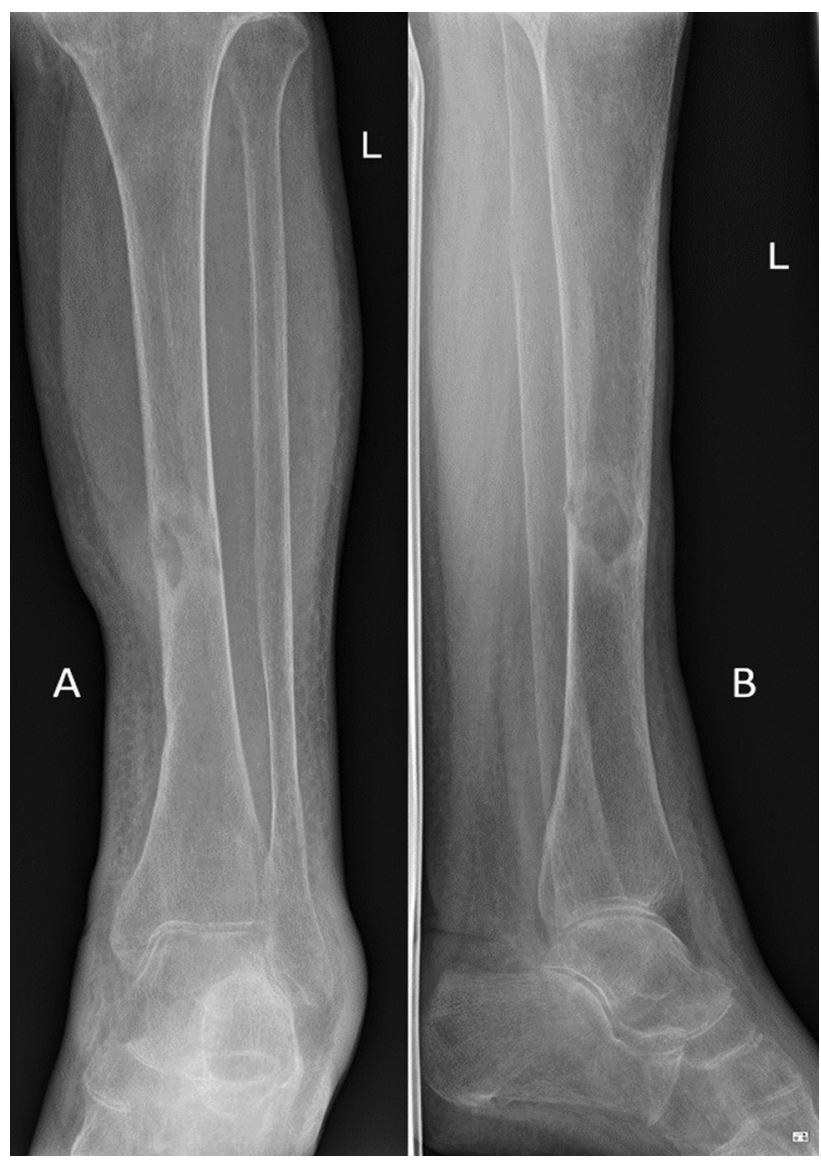

Figure 1. X-ray with an anterior-posterior view (A) and lateral view (B) of the osteolytic lesion in the tibial shaft with cortical bone destruction along with moth-eaten features.

(norm 0.81-1.45 mmol/l), albumin was 3,030 mg/dl (norm $3560-4,610 \mathrm{mg} / \mathrm{dl}$ ) and alkaline phosphatase activity was 676 IU/1 (norm 35-104 IU/1). In view of the given laboratory findings, careful re-evaluation of the biopsy indicated a brown tumor (Figure 3). Endocrinological, gastrological, and dental consultation were performed and previously unknown hyperparathyroidism with normocalcemia, vitamin D deficiency, and latent hypothyroidism was diagnosed.

The patient was presented to the interdisciplinary orthopaedic-oncological board and in a synopsis of the clinical, radiological as well as pathological, and laboratory findings, the decision was made for surgical treatment with an intramedullary nail osteosynthesis (Figure 4). Vitamin D was substituted.

Immediately after the operation the calcium levels clearly slipped away, but the peri- and post-operative course was uncomplicated and the patient was able to be fully mobilised in a satisfactory manner. After two weeks of hospitalisation, the patient was discharged to home care in good general condition. 


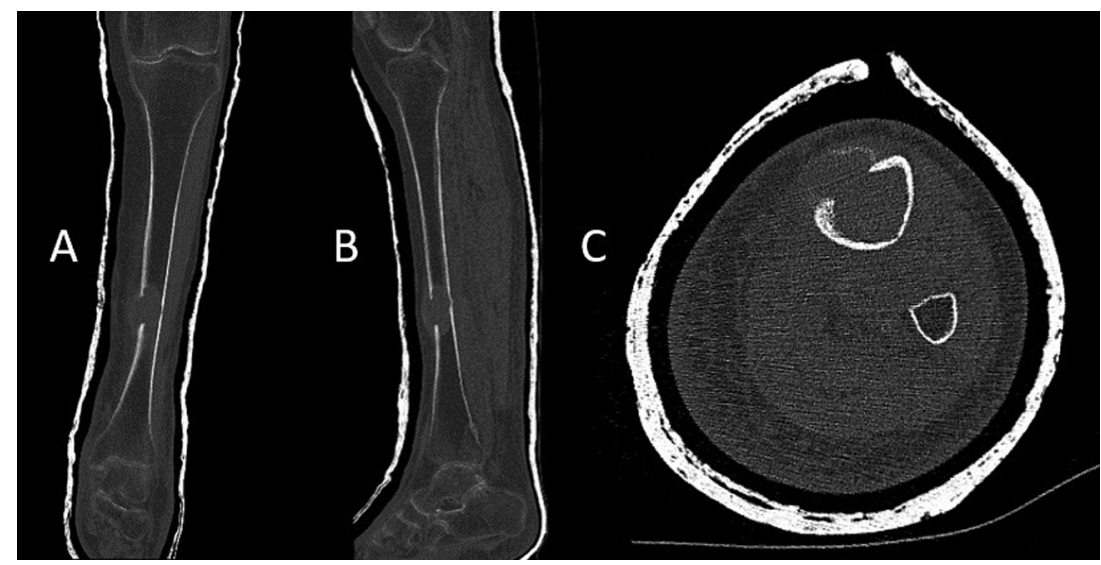

Figure 2. CT scan with coronary $(A)$, sagittal $(B)$ and axial $(C)$ view of the bone lesion in the tibial shaft with soft tissue components. Soft tissue involvement can be clearly seen.
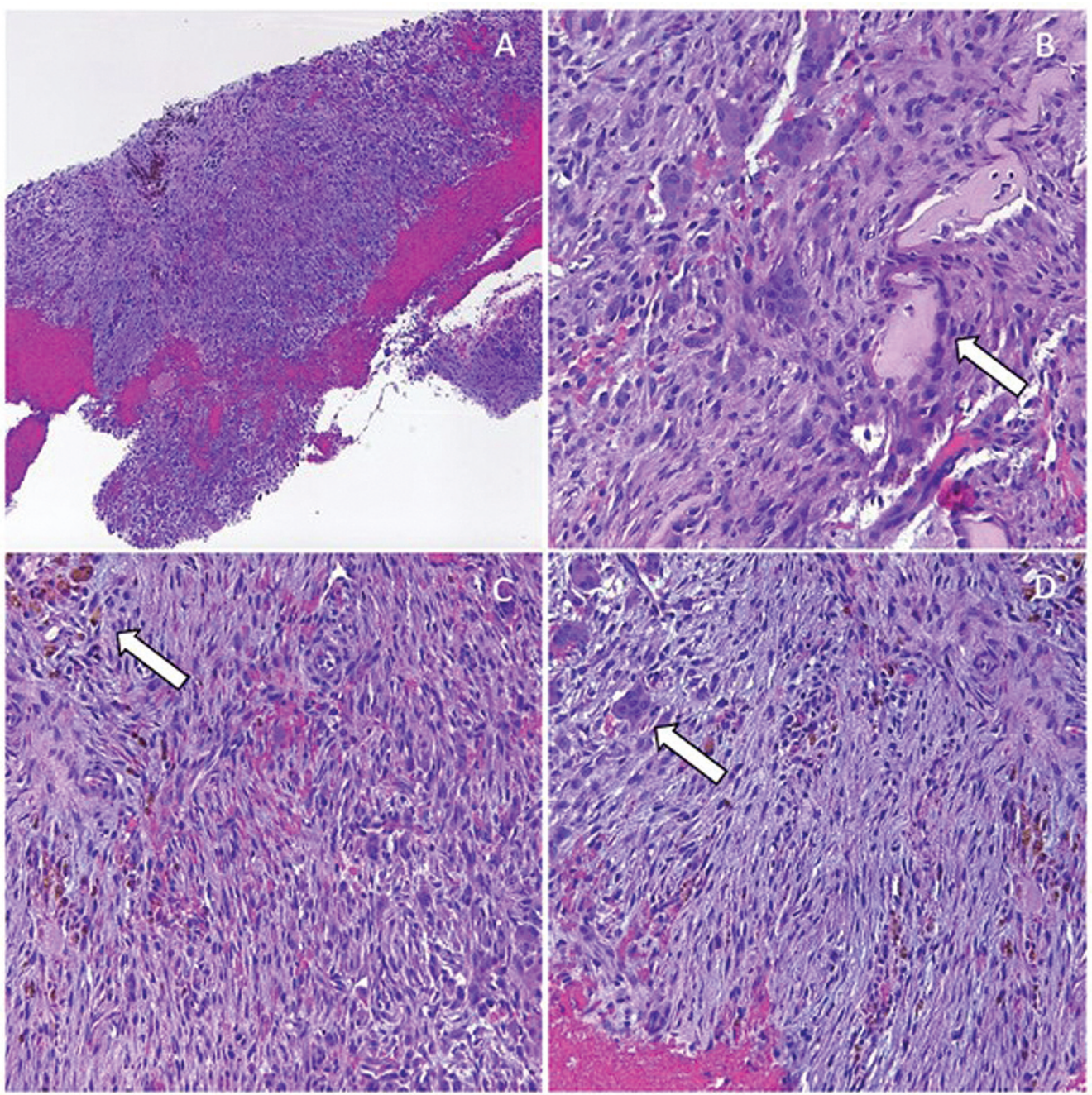

Figure 3. Histology of bone biopsy shows brown tumor with bland spindle cell proliferation, brown pigmentation, multinucleated giant cells, signs of bone resorption and haemorrhage. A) biopsy overview in $\mathrm{HE}$ at 50x, B) signs of bone resorption, HE 100x, C) brown pigmentation in macrophages, HE 100x, D) multinucleated giant cells, HE 100x. 
Table I. Summary of the literature review illustrating characteristics of patients with brown tumor [reference values according to the National Library of Medicine (19)].

\begin{tabular}{|c|c|c|c|c|c|c|c|c|c|c|}
\hline No. & Author & Year & Age & Gender & Localisation & Cases & $\begin{array}{c}\text { Serum } \\
\text { calcium } \\
{[\mathrm{mmol} / \mathrm{l}]} \\
\text { normal range } \\
2.20-2.55\end{array}$ & $\begin{array}{c}\text { Serum } \\
\text { phosphorus } \\
\text { [mmol/1] } \\
\text { normal range } \\
0.81-1.45\end{array}$ & $\begin{array}{c}\text { Parathyroid } \\
\text { hormone } \\
\text { [pg/ml] } \\
\text { normal range } \\
15-65\end{array}$ & $\begin{array}{c}\text { Alkaline } \\
\text { phosphatase } \\
\text { [IU/1] } \\
\text { normal range } \\
\text { 35-104 }\end{array}$ \\
\hline 1 & Psaila (20) & 2020 & 35 & Female & $\begin{array}{l}\text { Maxilla, skull, scapula } \\
\text { and both femora }\end{array}$ & 1 & 3.49 & 0.60 & 918 & n.a. \\
\hline 2 & Ngo (21) & 2021 & 35 & Female & Iliac bone and femur & 1 & 3.57 & 0.51 & 1,497 & 339 \\
\hline 3 & Diacinti (22) & 2020 & 19 & Male & Left mandible & 1 & 4.03 & 0.71 & 1,028 & 442 \\
\hline 4 & Dhaniwala (23) & 2020 & 28 & Female & Both femora and pelvis & 1 & 2.69 & n.a. & 1,632 & 1,686 \\
\hline 5 & Shaaban (24) & 2020 & 37 & Male & Maxilla, spine & 1 & n.a. & n.a. & 1900 & n.a. \\
\hline 6 & Han (25) & 2020 & 53 & Female & Rib & 1 & 3.67 & 0.70 & 528 & 455 \\
\hline 7 & Wiederkehr (26) & 2020 & 33 & Female & Ribs, spine & 1 & 2.58 & 1.29 & 2,476 & 519 \\
\hline 8 & Gosavi (27) & 2020 & 29 & Female & Mandible & 1 & 3.10 & 0.45 & n.a. & 2,182 \\
\hline 9 & Lenherr-Taube (28) & 2020 & 13 & Male & $\begin{array}{l}\text { Multifocal lesions } \\
\text { throughout the axial and } \\
\text { appendicular skeleton }\end{array}$ & 1 & 3.85 & 0.68 & 980 & 1,245 \\
\hline 10 & Xu W. (12) & 2019 & 30 & Female & $\begin{array}{l}\text { Skull, mandible, } \\
\text { spine, scapula }\end{array}$ & 1 & 2.87 & 0.37 & 1,805 & n.a. \\
\hline 11 & Manjunatha (29) & 2019 & 22 & Female & Mandible & 1 & 3.13 & n.a. & 1,828 & 1,378 \\
\hline 12 & Xu B. (30) & 2020 & 49 & Female & Mandible & 1 & 2.81 & 0.66 & 916.0 & n.a. \\
\hline 13 & $\mathrm{Hu}(31)$ & 2019 & 50 & Female & Femur, humerus, spine & 1 & 2.61 & n.a. & 1,811 & n.a. \\
\hline 14 & Aslan (32) & 2018 & 14 & Female & Tibia, femur & 1 & 3.35 & 0.72 & 1,441 & 636 \\
\hline 15 & Zou (33) & 2018 & 26 & Female & Mandible, maxilla, ribs & 1 & 3.09 & 0.62 & 267 & 397 \\
\hline 16 & Goyal (34) & 2018 & 16 & Female & Femur & 1 & 1.98 & 0.90 & 840 & 1,324 \\
\hline 17 & Panagopoulos (35) & 2018 & 53 & Male & $\begin{array}{l}\text { Ulna, radius, tibia, } \\
\text { metacarpus, humerus }\end{array}$ & 1 & 3.63 & 0.74 & 1,453 & n.a. \\
\hline 18 & Mellouli (36) & 2018 & 45 & Female & Mandible & 1 & 2.30 & 1.30 & 82 & n.a. \\
\hline 19 & Garla (37) & 2018 & 50 & Female & Knee, femur, iliac bone & 1 & 3.08 & n.a. & 1,810 & n.a. \\
\hline 20 & Baig (38) & 2018 & 77 & Female & Femur, ischium & 1 & 2.80 & n.a. & 3,842 & n.a. \\
\hline 21 & Ojha (39) & 2018 & 62 & Female & Mandible & 1 & 3.16 & n.a. & 516 & $\begin{array}{l}\text { "within } \\
\text { normal limits" }\end{array}$ \\
\hline 22 & Satpathy (40) & 2017 & 15 & Female & Mandible & 1 & 3.08 & 6.26 & 2,269 & 3,319 \\
\hline 23 & Talukder (18) & 2017 & 49 & Female & Mandible & 1 & 3.51 & 0.94 & 1,000 & n.a. \\
\hline \multirow[t]{4}{*}{24} & Misiorowski (17) & 2017 & 28 & Male & Clavicle & 4 & 3.30 & 0.48 & 1,560 & 624 \\
\hline & & & 56 & Female & Knee & & 3.45 & 0.68 & 336 & 356 \\
\hline & & & 58 & Male & Humerus & & 3.55 & 0.58 & 458 & 459 \\
\hline & & & 23 & Male & Pubic bone & & 3.65 & 0.94 & n.a. & 1,035 \\
\hline 25 & Shekhawat (41) & 2017 & 31 & Female & Metatarsal bone & 1 & 2.80 & 0.65 & 2,543 & 1,049 \\
\hline 26 & Vaishya (42) & 2017 & 25 & Female & Tibia & 1 & 2.25 & 1.39 & 495 & 450 \\
\hline 27 & Jervis (43) & 2017 & 58 & Female & $\begin{array}{c}\text { Multiple osteolyses } \\
\text { in humerus, knee, } \\
\text { clavicle, ribs, } \\
\text { femur, hand }\end{array}$ & 1 & 2.65 & 2.01 & 400 & 341 \\
\hline 28 & Schnyder (9) & 2017 & 72 & Female & $\begin{array}{l}\text { Os ilium and } \\
\text { acetabulum, ribs }\end{array}$ & 1 & 3.55 & 0.56 & 1,466 & 189 \\
\hline 29 & Park (44) & 2016 & 57 & Female & Both femora & 1 & 3.63 & 0.65 & 2,720 & 2,417 \\
\hline 30 & Batur (45) & 2016 & 33 & Male & Os pubis & 1 & 2.25 & n.a. & 223 & n.a. \\
\hline 31 & Riestra Fernández (46) & 2017 & 58 & Male & Both tibiae, ribs & 1 & 3.85 & 0.90 & 1,027 & 335 \\
\hline 32 & Hussain (47) & 2016 & 21 & Female & $\begin{array}{l}\text { Mandible, maxilla, } \\
\text { sternum, proximal tibia }\end{array}$ & 1 & 2.16 & 0.71 & 1,653 & 875 \\
\hline 33 & Sathyakumar (40) & 2016 & 28 & Female & Pelvis, both femora & 1 & 3.10 & 0.65 & $>1,900$ & 1,112 \\
\hline
\end{tabular}

\section{Discussion}

According to the literature (Table I), OFC is a rare presentation of both primary and secondary hyperparathyroidism (2), and was first described by von Recklinghausen in 1891 (1). Due to the elevated parathyroid hormone, there is excessive activation of osteoclasts, which can lead to transformation and degradation processes in the bones (10). This forms a cystic 


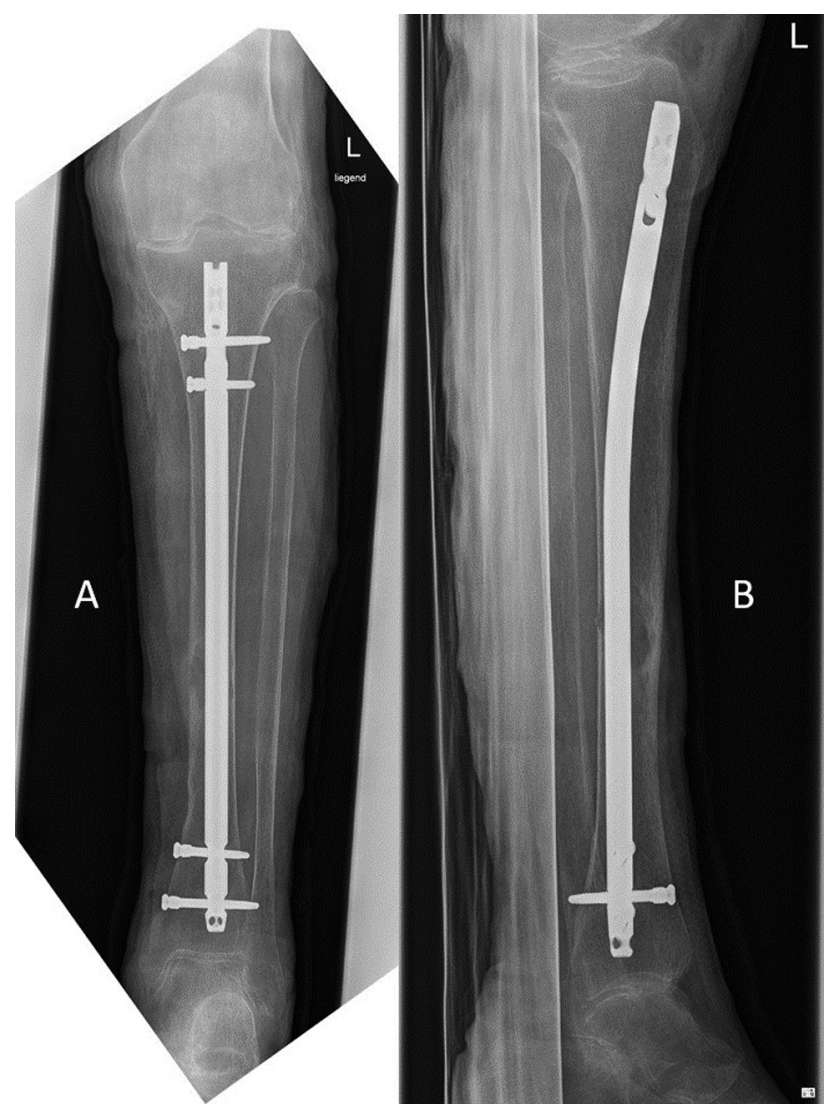

Figure 4. X-ray with an anterior-posterior view (A) and lateral view (B) after implantation of an intramedullary tibial nail with osteolysis in the middle tibia.

change in the bone, which appears as a brown tumor and can cause an increased risk of fracture. In everyday clinical practice, the presence of hyperparathyroidism is in some cases diagnosed only after a pathological fracture has occurred. Histopathologically, the tumor can be assigned to the group of giant cell tumors (11). However, because of its rarity and the way it typically presents, metastatic cancer is often the first diagnostic impression (2).

OFC is uncommon in clinical practice, and its clinical symptoms and imaging findings are easily confused with malignant bone tumors. However, brown tumors are difficult to diagnose, leading to delayed treatment (12). Histology cannot guarantee a certain diagnosis, as other lesions, such as giant cell tumor, giant cell granuloma, aneurysmal bone cyst, and some variants of osteosarcomas show similar macroscopical and microscopical features because all these conditions contain giant-cell lesions $(2,13,14)$. Moreover, if hypercalcemia is present, the first impression is often that of malignancy itself (2). Even positron emission tomography (PET) scanning does not reliably distinguish between a skeletal malignancy and benign disease (15).
Multiple skeletal lesions (brown tumors) represent a rare clinical manifestation of prolonged hyperparathyroidism and are reported in approximately $2 \%-5 \%$ of patients with primary hyperparathyroidism $(12,16)$. We therefore performed a literature search on the characteristics of bone brown tumors caused by secondary to primary hyperparathyroidism. We gathered and searched for similar cases reported from 2016 to 2021. The primary database used for the search was PubMed. As suggested in previous studies, further publications were identified by crosssearching the article references. Thus, a backward and forward citation search was performed. PubMed was searched as follows: with the keywords (brown tumor) AND (primary hyperparathyroidism) AND (case report). Published articles during 2016-2021 were included. Meta-analyses and non-English-language articles were excluded. Finally, only articles where full text was available were included. The characteristics of all cases are shown in Table I.

Serum calcium, parathyroid hormone, and alkaline phosphatase were significantly elevated in most patients. Serum phosphorus was correspondingly reduced. In most cases, osteolytic lesions were classified as primary or metastatic tumors. The authors report that PHPT with osteitis fibrosa was hardly ever diagnosed in all of the cases and symptomatic hypercalcaemia was considered to be an accompanying symptom of the malignancy itself (17). In some cases, palliative cancer treatment was initiated and even amputation of the leg was considered (17). In another case, where a patient suffered from recurrent painful jaw swelling, an incision biopsy of the lesion suggested giant cell reparative granuloma and the patient underwent transoral curettage of the lesions (18). Only when the patient again sought clinical attention for recurrent jaw swelling further investigation was performed and blood biochemistry revealed abnormally high serum calcium, relatively low phosphate and grossly elevated parathyroid levels (18).

In accordance with most cases reported in the literature, the first diagnosis in the current case was bone metastasis and the patient was presented for haemato-oncological consultation. A sonographically targeted biopsy was performed and even after bone biopsy diagnosis was not clear. After a whole-body CT scan and a CT scan of the skull and neck, which revealed numerous osteolytic destructions with osteolytic defects, the differential diagnosis of multiple myeloma was established. Now, one might possibly ask how in the synopsis of the radiological and laboratory findings an "obvious" brown tumor could not be recognised. These misinterpretations of the radiological imaging and the resulting mistreatment may be explained by the rarity of these skeletal lesions.

Diagnosis of a brown tumor could especially be difficult, when there is a history of a malignant tumour disease in a patient's medical record (9). Bone lesions could be erroneously interpreted as bone metastases. Even if a brown tumor is 
suspected, there could be great concern not to miss a concomitant malignant disease (9). This is aggravated by the fact that the first biopsy, like in the presented case, is sometimes not diagnostic for either malignancy or brown tumor. Therefore, biochemistry laboratory examinations might in some cases be more useful than biopsies and histopathology (9).

In conclusion, brown tumors are a rare clinical manifestation of prolonged hyperparathyroidism. As seen from the literature, they are often overseen and misinterpreted. In some cases, even palliative cancer treatment or amputation was initiated. Therefore, we conclude that in the case of hypercalcemia and lytic lesions, primary hyperparathyroidism should always be considered as a differential diagnosis. Further biochemical evaluation and bone scan can help in the management. We strongly suggest and absolutely encourage physicians to admit patients with an unclear osteolytic lesion and pathological fracture to a tertiary orthopaedic oncological center for further treatment and diagnostics.

\section{Conflicts of Interest}

The Authors declare that they did not receive any specific grant from funding agencies in the public, commercial, or not-for-profit sectors. The Authors declare that they have no conflicts of interest in relation to this study.

\section{Authors' Contributions}

All of the Authors made relevant contributions to the conception of the study, to the acquisition, analysis or interpretation of data, and to the development of the final work. Each of the Authors has read and concurs with the content of the final manuscript.

\section{Acknowledgements}

Professional language editing of the manuscript by Mary Margreiter is acknowledged. Radiological images are used with kind permission of the local Department of Radiology.

\section{References}

1 Von Recklinghausen F: Die fibrose oder deformierende Ostitis, die Osteomalacie und die osteoplastische Carcinose in ihren gegenseitigen Beziehungen Festschrift fur Rudolf Virchow. Berlin: Reimer, 1891.

2 Misiorowski W and Bilezikian JP: Osteitis fibrosa cystica. JBMR Plus 4(9): e10403, 2020. PMID: 32995697. DOI: $10.1002 / \mathrm{jbm} 4.10403$

3 Silverberg SJ and Bilezikian JP: Evaluation and management of primary hyperparathyroidism. J Clin Endocrinol Metab 81(6): 20362040, 1996. PMID: 8964825. DOI: 10.1210/jcem.81.6.8964825

4 Chew FS and Huang-Hellinger F: Brown tumor. AJR Am J Roentgenol 160(4): 752, 1993. PMID: 8456657. DOI: 10.2214/ ajr.160.4.8456657

5 Lang S: Differenzialdiagnose riesenzellreicher Knochenläsionen. In: Pathologe. Springer, pp. 245-249, 2008.
6 Hsieh MC, Ko JY and Eng HL: Pathologic fracture of the distal femur in osteitis fibrosa cystica simulating metastatic disease. Arch Orthop Trauma Surg 124(7): 498-501, 2004. PMID: 15168133. DOI: $10.1007 / \mathrm{s} 00402-004-0697-y$

7 Phulsunga RK, Parghane RV, Kanojia RK, Gochhait D, Sood A, Bhattacharya A and Mittal BR: Multiple brown tumors caused by a parathyroid adenoma mimicking metastatic bone disease from giant cell tumor. World J Nucl Med 15(1): 56-58, 2016. PMID: 26912981. DOI: 10.4103/1450-1147.167598

8 Ullah E, Ahmad M, Ali SA and Redhu N: Primary hyperparathyroidism having multiple Brown tumors mimicking malignancy. Indian J Endocrinol Metab 16(6): 1040-1042, 2012. PMID: 23226663. DOI: 10.4103/2230-8210.103037

9 Schnyder MA, Stolzmann P, Huber GF and Schmid C: A patient with a history of breast cancer and multiple bone lesions: a case report. J Med Case Rep 11(1): 127, 2017. PMID: 28476174. DOI: 10.1186/s13256-017-1296-1

10 Silva BC and Bilezikian JP: Skeletal abnormalities in hypoparathyroidism and in primary hyperparathyroidism. Rev Endocr Metab Disord, 2020. PMID: 33200346. DOI: 10.1007/s11154-020-09614-0

11 Troendlin F, Schildhauer TA and Ramczykowski T: GMS I German Congress of Orthopedic and Trauma Surgery (DKOU 2017) I Der braune Tumor- eine knöcherne Manifestation bei Hyperparathyreoidismus, 2017. Available at: https://www.egms.de/ static/en/meetings/dkou2017/17dkou806.shtml [Last accessed on April 23, 2021]

12 Xu W, Qu Y, Shi W, Ma B, Jiang H, Wang Y, Qu N and Zhu Y: Multiple bone brown tumor secondary to primary hyperparathyroidism: a case report and literature review. Gland Surg 8(6): 810-816, 2019. PMID: 32042691. DOI: 10.21037/gs.2019.11.14

13 Meydan N, Barutca S, Guney E, Boylu S, Savk O, Culhaci N and Ayhan M: Brown tumors mimicking bone metastases. J Natl Med Assoc 98(6): 950-953, 2006. PMID: 16775919.

14 Vera L, Dolcino M, Mora M, Oddo S, Gualco M, Minuto F and Giusti M: Primary hyperparathyroidism diagnosed after surgical ablation of a costal mass mistaken for giant-cell bone tumor: a case report. J Med Case Rep 5: 596, 2011. PMID: 22204520. DOI: 10.1186/1752-1947-5-596

15 Park SB, Park JM, Moon SH, Cho YS, Sun JM, Kim BT and Lee KH: Role of 18F-FDG PET/CT in patients without known primary malignancy with skeletal lesions suspicious for cancer metastasis. PLoS One 13(5): e0196808, 2018. PMID: 29746513. DOI: 10.1371/journal.pone.0196808

16 Azria A, Beaudreuil J, Juquel JP, Quillard A and Bardin T: Brown tumor of the spine revealing secondary hyperparathyroidism. Report of a case. Joint Bone Spine 67(3): 230-233, 2000. PMID: 10875324.

17 Misiorowski W, Czajka-Oraniec I, Kochman M, Zgliczyński W and Bilezikian JP: Osteitis fibrosa cystica-a forgotten radiological feature of primary hyperparathyroidism. Endocrine 58(2): 380-385, 2017. PMID: 28900835. DOI: $10.1007 / \mathrm{s} 12020-$ 017-1414-2

18 Talukder S, Behera A, Bhadada SK and Mitra S: Giant mediastinal parathyroid adenoma presenting as bilateral brown tumour of mandible: a rare presentation of primary hyperparathyroidism. BMJ Case Rep 2017: bcr2017220722, 2017. PMID: 29066636. DOI: 10.1136/bcr-2017-220722

19 National Library of Medicine - National Institutes of Health. Available at: https://www.nlm.nih.gov/ [Last accessed on March 23, 2021] 
20 Psaila A, Conti L, Azzopardi AP and Coppini DV: A brown tumor secondary to hyperparathyroidism in the maxilla, skull, scapula, and femora. Proc (Bayl Univ Med Cent) 34(1): 163-165, 2020. PMID: 33456187. DOI: 10.1080/08998280.2020.1826260

21 Ngo QX, Ngo DQ, Tran TD, Le DT, Hoang GN and Le QV: Multiple brown tumors with primary hyperparathyroidism mimicking bone metastases []. Int J Surg Case Rep 79: 375-378, 2021. PMID: 33516054. DOI: 10.1016/j.ijscr.2021.01.002

22 Diacinti D, Cipriani C, Biamonte F, Pepe J, Colangelo L, Kripa E, Iannacone A, Orlandi M, Guarnieri V, Diacinti D and Minisola S: Imaging technologies in the differential diagnosis and follow-up of brown tumor in primary hyperparathyroidism: Case report and review of the literature. Bone Rep 14: 100745, 2020. PMID: 33506077. DOI: 10.1016/j.bonr.2020.100745

23 Dhaniwala NS and Dhaniwala MN: Multiple Brown tumors in a case of primary hyperparathyroidism with pathological fracture in femur. J Orthop Case Rep 10(6): 49-53, 2020. PMID: 33489969. DOI: 10.13107/jocr.2020.v10.i06.1872

24 Shaaban ATE, Ibrahem M, Saleh A, Haider A and Alyafai A: Brown tumor due to primary hyperparathyroidism resulting in acute paraparesis: Case report and literature review. Surg Neurol Int 11: 355, 2020. PMID: 33194288. DOI: 10.25259/SNI_653_2020

25 Han L and Zhu XF: Parathyroid adenoma combined with a rib tumor as the primary disease: A case report. World J Clin Cases 8(19): 4681-4687, 2020. PMID: 33083434. DOI: 10.12998/wjcc. v8.i19.4681

26 Wiederkehr M: Brown tumor complicating end-stage kidney disease. Clin Nephrol Case Stud 8: 72-79, 2020. PMID: 33062583. DOI: $10.5414 / \mathrm{CNCS} 110195$

27 Gosavi S, Kaur H and Gandhi P: Multifocal osteolytic lesions of jaw as a road map to diagnosis of brown tumor of hyperparathyroidism: A rare case report with review of literature. J Oral Maxillofac Pathol 24(Suppl 1): S59-S66, 2020. PMID: 32189907. DOI: 10.4103/jomfp.JOMFP_319_19

28 Lenherr-Taube N, Lam CK, Vali R, Shammas A, Campisi P, Zawawi F, Somers GR, Stimec J, Mete O, Wong AK and Sochett E: Severe primary hyperparathyroidism caused by parathyroid carcinoma in a 13-year-old child; novel findings from HRpQCT. JBMR Plus 4(3): e10324, 2020. PMID: 32161840. DOI: $10.1002 / \mathrm{jbm} 4.10324$

29 Manjunatha BS, Purohit S, Harsh A and Vangala N: A complex case of brown tumors as initial manifestation of primary hyperparathyroidism in a young female. J Oral Maxillofac Pathol 23(3): 477, 2019. PMID: 31942141. DOI: 10.4103/jomfp.JOMFP_166_19

$30 \mathrm{Xu} \mathrm{B}, \mathrm{Yu} \mathrm{J}, \mathrm{Lu} \mathrm{Y}$ and Han B: Primary hyperparathyroidism presenting as a brown tumor in the mandible: a case report. BMC Endocr Disord 20(1): 6, 2020. PMID: 31931802. DOI: 10.1186/s12902-019-0480-2

$31 \mathrm{Hu}$ J, He S, Yang J, Ye C, Yang X and Xiao J: Management of brown tumor of spine with primary hyperparathyroidism: A case report and literature review. Medicine (Baltimore) 98(14): e15007, 2019. PMID: 30946329. DOI: 10.1097/MD.0000000000015007

32 Aslan S, Bilgici MC, Bernay RF, Aydin HM and Selcuk MB: Parathyroid adenoma presenting with multiple Brown tumors in an adolescent patient. North Clin Istanb 5(4): 361-364, 2018 PMID: 30859169. DOI: 10.14744/nci.2018.35693

33 Zou H, Song L, Jia M, Wang L and Sun Y: Brown tumor of multiple facial bones associated with primary hyperparathyroidism: A clinical case report. Medicine (Baltimore) 97(33): e11877, 2018. PMID: 30113484. DOI: 10.1097/MD.0000000000011877
34 Goyal A, Boro H and Khadgawat R: Brown tumor as an index presentation of severe vitamin D deficiency in a teenage girl. Cureus 10(5): e2722, 2018. PMID: 30079288. DOI: 10.7759/cureus.2722

35 Panagopoulos A, Tatani I, Kourea HP, Kokkalis ZT, Panagopoulos $\mathrm{K}$ and Megas P: Osteolytic lesions (brown tumors) of primary hyperparathyroidism misdiagnosed as multifocal giant cell tumor of the distal ulna and radius: a case report. J Med Case Rep 12(1): 176, 2018. PMID: 29936913. DOI: 10.1186/s13256-018-1723-y

36 Mellouli N, Belkacem Chebil R, Darej M, Hasni Y, Oualha L and Douki N: Mandibular osteitis fibrosa cystica as first sign of vitamin D deficiency. Case Rep Dent 2018: 6814803, 2018. PMID: 29850279. DOI: $10.1155 / 2018 / 6814803$

37 Garla VV, Akhtar I, Salim S and Subauste A: Osteitis fibrosa cystica masquerading as bone neoplasm. BMJ Case Rep 2018: bcr2018224546, 2018. PMID: 29735505. DOI: 10.1136/bcr2018-224546

38 Baig MN, Mac Dhaibheid C and Shannon FJ: Hip fracture in a patient with primary hyperparathyroidism: medical and surgical lessons. Cureus 10(1): e2104, 2018. PMID: 29581916. DOI: 10.7759 /cureus. 2104

39 Ojha SS, Valecha J, Sharma A and Nilkanthe R: Role of fine needle aspiration cytology in diagnosis of brown tumor secondary to parathyroid adenoma. J Lab Physicians 10(1): 118120, 2018. PMID: 29403220. DOI: 10.4103/JLP.JLP_3_17

40 Sathyakumar S, Cherian KE, Shetty S and Paul TV: Impact of curative surgery on bone in a patient with osteitis fibrosa cystica of primary hyperparathyroidism. BMJ Case Rep 2016: bcr2016214970, 2016. PMID: 27030464. DOI: 10.1136/bcr2016-214970

41 Shekhawat VS and Bhansali A: Vanishing metatarsal: a rare manifestation of primary hyperparathyroidism. BMJ Case Rep 2017: bcr2017220676, 2017. PMID: 28765188. DOI: 10.1136/ bcr-2017-220676

42 Vaishya R, Agarwal AK, Vijay V and Vaish A: A brown tumor of tibial diaphysis masquerading as malignancy. Cureus 9(6): e1319, 2017. PMID: 28698829. DOI: 10.7759/cureus.1319

43 Jervis L, James M, Howe W and Richards S: Osteolytic lesions: osteitis fibrosa cystica in the setting of severe primary hyperparathyroidism. BMJ Case Rep 2017: bcr2017220603, 2017. PMID: 28554885. DOI: 10.1136/bcr-2017-220603

44 Park SH, Kong GM, Kwon YU and Park JH: Pathologic fracture of the femur in brown tumor induced in parathyroid carcinoma: a case report. Hip Pelvis 28(3): 173-177, 2016. PMID: 27777921. DOI: $10.5371 /$ hp.2016.28.3.173

45 Batur A: Primary hyperparathyroidism causing putty kidney with brown tumor located in the pubic ramus. Saudi J Kidney Dis Transpl 27(5): 1033-1036, 2016. PMID: 27752017. DOI: 10.4103/1319-2442.190883

46 Riestra Fernández M, Suárez Gutiérrez L, Martínez M and Diéguez Felechosa M: Primary hyperparathyroidism: An unusual presentation. Reumatol Clin 13(4): 246-247, 2017. PMID: 27528246. DOI: 10.1016/j.reuma.2016.07.004

47 Hussain M and Hammam M: Management challenges with brown tumor of primary hyperparathyroidism masked by severe vitamin D deficiency: a case report. J Med Case Rep 10: 166, 2016. PMID: 27277007. DOI: 10.1186/s13256-016-0933-4

Received April 8, 2021

Revised April 22, 2021 Accepted April 23, 2021 